\title{
A measuring stand for a ducted fan aircraft propulsion unit
}

\author{
David Hlaváček ${ }^{1, a}$ \\ ${ }^{1}$ Department of Aerospace Engineering, Faculty of Mechanical Engineering, Czech Technical University in Prague, \\ Karlovo náměstí 13, 12135 Praha 2, Czech Republic
}

\begin{abstract}
The UL-39 ultra-light aircraft which is being developed by the Department of Aerospace Engineering, Faculty of Mechanical Engineering, Czech Technical University in Prague, is equipped with an unconventional ducted fan propulsion unit. The unit consists of an axial fan driven by a piston engine and placed inside a duct ended with a nozzle. This article describes the arrangement of a modernised measuring stand for this highly specific propulsion unit which will be able to measure the fan pressure ratio and velocity field in front of and behind the fan and its characteristic curve.
\end{abstract}

\section{Introduction}

The UL-39 aircraft is being developed by a team of students and employees of the Institute of Aerospace Engineering, Faculty of Mechanical Engineering, Czech Technical University in Prague. Its propulsion unit consists of a single-stage axial fan in stator-rotor arrangement placed in a duct inside the fuselage of the aircraft. The duct ends with a nozzle. The fan is driven by a piston engine. In the past, a Yamaha YZF-R1 engine was used to drive the measuring stand placed in the laboratories of the Institute. For this engine, the present fan was designed. A new engine, the BMW S1000RR was bought in 2011 for use in the flying prototype of the aircraft. This engine has the advantage of a lighter weight along with a higher maximum horsepower.

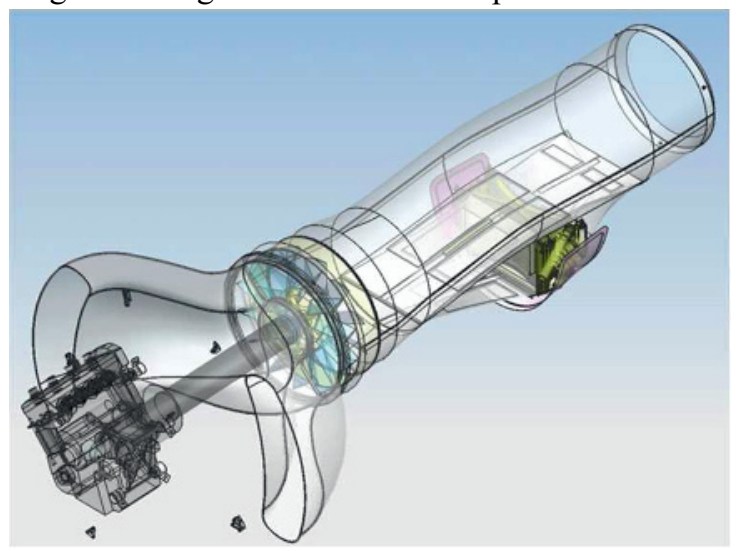

Figure 1. Model of the UL-39 propulsion unit.

In order to optimize the operating conditions of the propulsion unit, a new fan will be designed. The main objective of its design was a higher propulsion unit thrust, a higher efficiency while lowering the noise level at the same time.

The air passes through a pair of inlet channel to a stator guide vane. The very specific flow conditions inside the short and strongly curved channel led to an unconventional inlet channel design. Its splitting plane is twisted by an angle of $45 \mathrm{deg}$ around the longitudinal axis of the aircraft (see figure 3 ). Along with the stator guide vane, this arrangement ensures an even distribution of rotor angles of attack in the design point (figure 4).

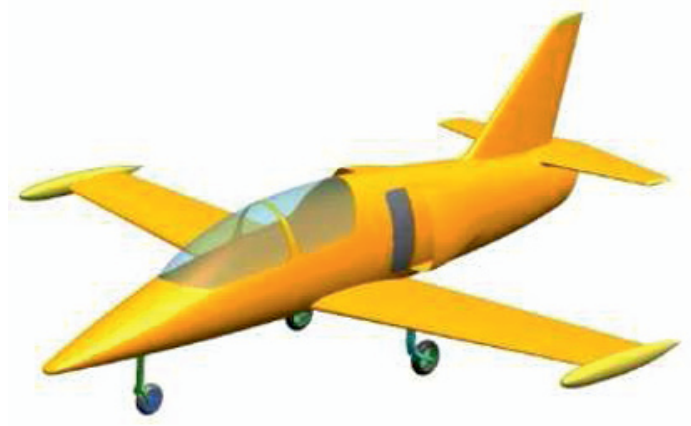

Figure 2. Model of the UL-39 aircraft.

The flow field inside the ducted fan propulsion unit, especially the inlet channel, has already been investigated using CFD calculations and the method of materialized streamlines. An experimental investigation is being prepared now which should lead to the knowledge of velocity magnitudes (and an idea of its directions as well) downstream of the fan rotor and of the fan characteristic curve.

The measurement will be a part of the development of a new fan. At this time, it should validate the results of the previous design calculation.

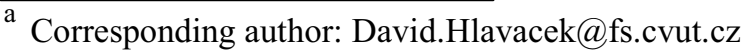




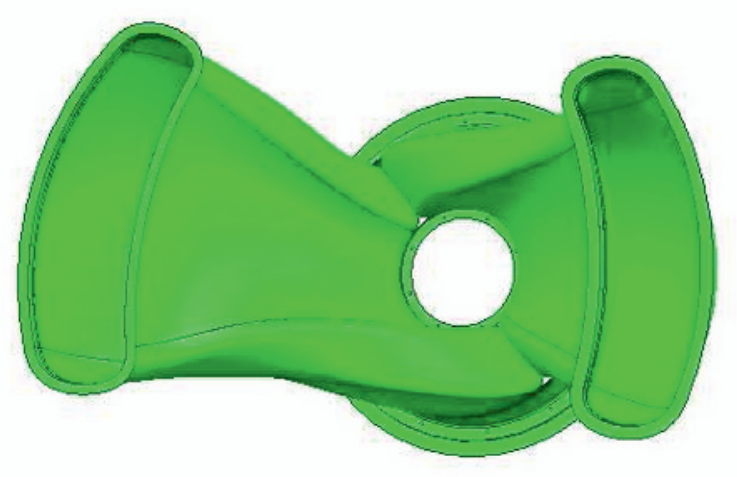

help of calculations performed in [1] and relationships describing the velocity field downstream of compressor blade vanes.

\subsection{Goal of the measurement}

The main goal of the measurement is determining the characteristic curve of the fan.

The characteristic curve describes the dependence of the fan pressure ratio on its flow rate and is one of the "
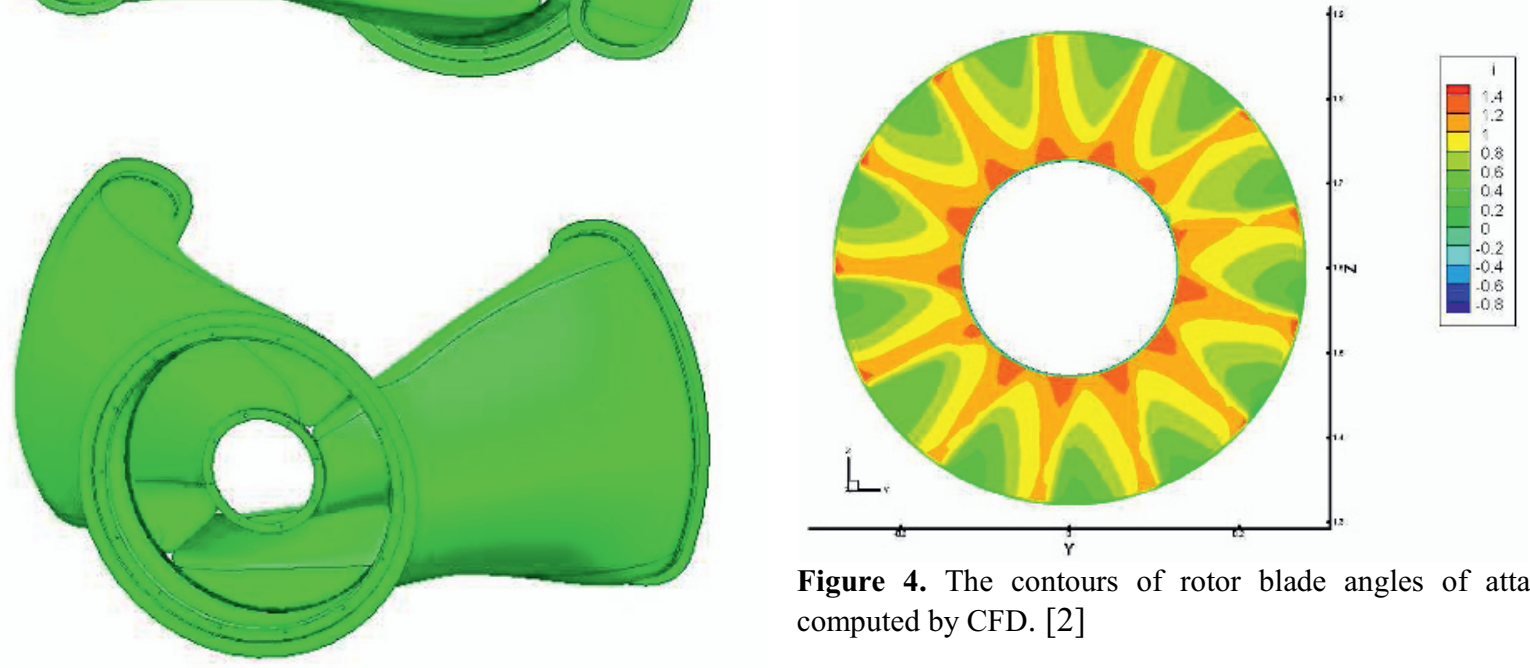

Figure 3. The twisted inlet channel of the propulsion unit.

The aim of this paper is to propose the method and instrumentation for measuring the velocity distribution downstream of the rotor and the fan characteristic curve.

\section{The measuring stand arrangement}

For measuring the fan's characteristic curve and its parameters in the design point, it is necessary to know the total pressure ratio (or difference) and mass or volume flow rate of air passing through the fan. Therefore, pressure and velocity sensing tubes will be used during the measurement. The instrumentation for measuring the velocity profile behind the fan rotor will be identical.

First, we need to evaluate the suitable places and conditions of the measurement. We will do so with the

Figure 4. The contours of rotor blade angles of attack as computed by CFD. [2]

fundamental means of indicating the fan's behaviour during operation. It determines the operating point of the fan and its reaction to any changes of the operating conditions. The fan characteristic curve is depicted in figure 16. Each branch of the characteristic curve corresponds to a respective shaft speed.

For measuring one branch of the characteristic curve, one needs to measure the total pressure upstream and downstream of the fan, and the air flow rate. Using a throttling device, the flow rate is then changed which leads to a change of the fan total pressure ratio.

\subsection{The points of measurement}

The choice of the suitable places for measuring the pressures and velocities is influenced by the unconventional arrangement of the propulsion unit
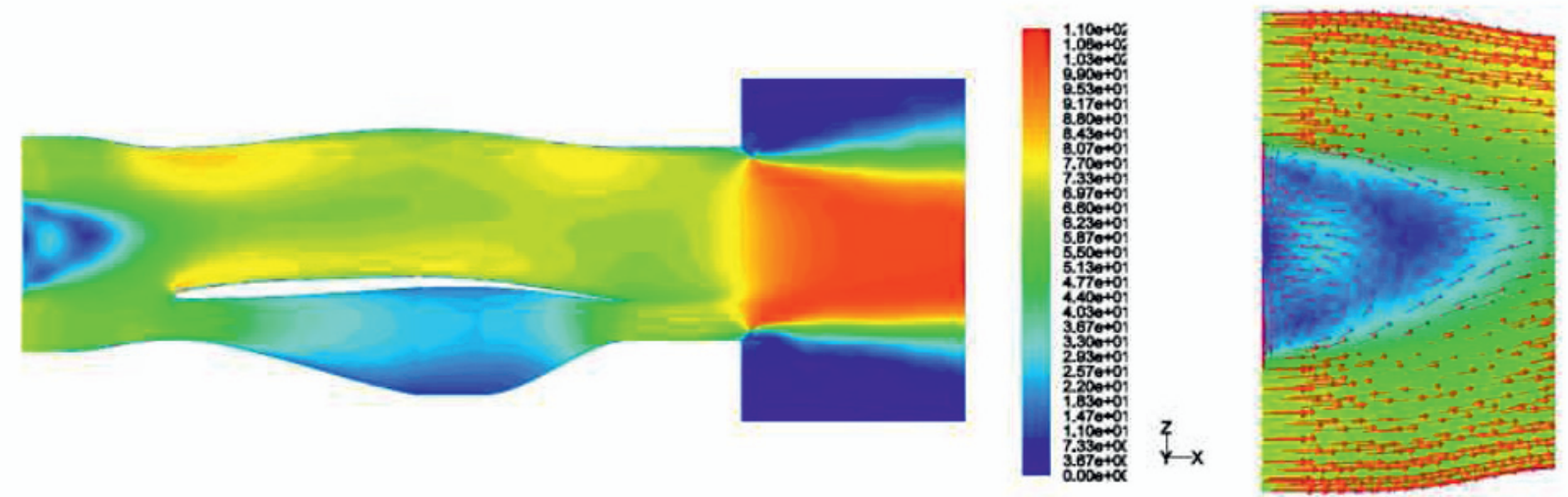

Figure 5. The velocity magnitudes in the outlet channel as computed by CFD. [3] 
(especially of its inlet channel) and the accessibility requirements. Therefore, the measurement will be made in both inlet channels and a plane in a certain distance downstream of the fan. A measuring plane upstream of the fan is not suitable for this type of measurement since the flow field is highly distorted there while our goal is to find the mean values of velocity in both space in time. Furthermore, this place is not easily accessible.

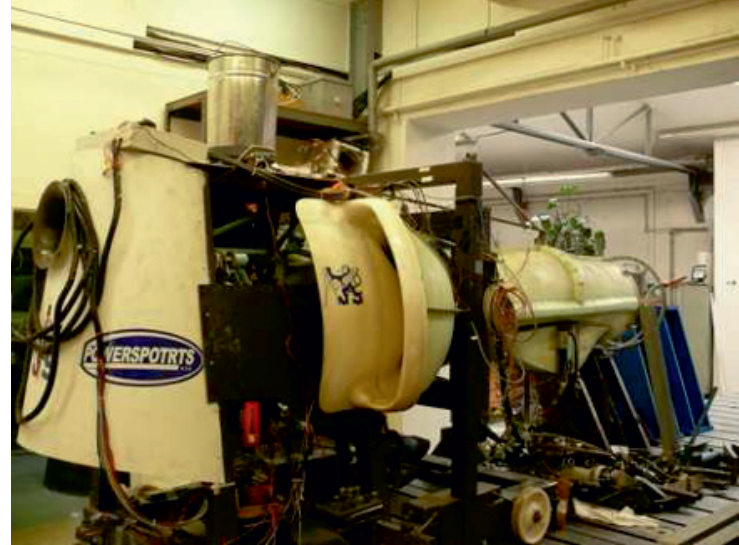

Figure 6. The present measuring stand of the propulsion unit.

There is another reason for this arrangement of measuring places. The operational parameters of the fan are affected by the design of the inlet channel to a great extent. Therefore, it is better to consider the fan and its inlet channel a compact unit rather than separate components.

The plane for placing the velocity sensing tubes in the inlet channel can be chosen considering only an easy access for mounting the tubes and their piping. Therefore, the measuring plane downstream of the fan rotor will be the chief subject of our interest. Its distance from the rotor blade vane depends on the presence of wakes behind the blades and hub, and, of course, on the arrangement of the outlet channel.

Since, for the reasons of weight, the hub of the fan is not equipped by any cone, the flow area downstream of the rotor increases suddenly. A cone-shaped wake forms in an area close to the rotor axis (see figure 5). According to the CFD calculations performed in [3], its length is approx. $350 \mathrm{~mm}$. The distance between the rotor exit and the inlet of the by-pass channel with a radiator in it (see also figure 5) is $410 \mathrm{~mm}$. The measuring plane should best be placed between these two distances. If it was placed further downstream, it would be necessary to account for the division of the channel in two branches. Moreover, the section of the channel is not circular anymore.

Now, we need to investigate the effect of the rotor blade wakes on the flow field in the area downstream of the fan. In the following paragraphs, the dimensions of the affected area will be calculated based on relatively simple models. The results will lead to a decision, whether it is possible to place the measuring plane in the above- mentioned distance downstream of the fan.

For determining the distance in which the influence of the rotor wakes will not be significant, a model published in [1] will be used.

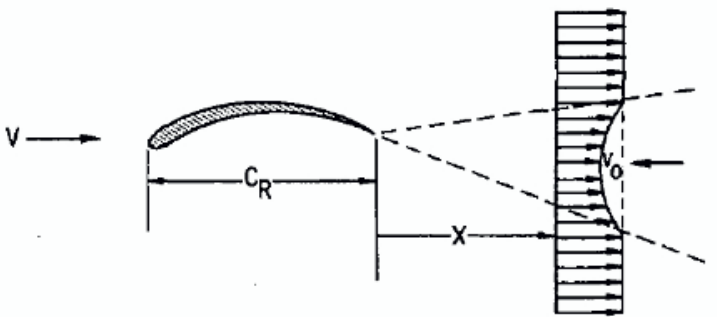

Figure 7. Model of a wake behind an airfoil. [1]

According to [1], the backflow velocity in a wake behind a rotor blade is a function of the blade drag coefficient and the axial distance behind it.

$$
\frac{v_{0}}{v_{\infty}} \propto \frac{\sqrt{c_{\mathrm{D}, \mathrm{R}}}}{\sqrt{\frac{x}{c_{\mathrm{R}}}}}
$$

Particularly, the author of [1] claims that, according to experiments performed, the relationship

$$
\frac{v_{0}}{v_{\infty}}=\frac{1.6 \sqrt{c_{\mathrm{D}, \mathrm{R}}}}{\sqrt{\frac{x}{c_{\mathrm{R}}}+0.025}}
$$

should best be used.

The ratio of velocities in the previous equation should be as close to zero as possible. The unknown quantity in this relationship is the distance denoted by $x$.

That rotor blade drag coefficient $c_{\mathrm{D}, \mathrm{R}}$ is not very often used to account for losses in a blade vane. More often, the total pressure loss coefficient $\zeta_{\mathrm{R}}$ according to Ainley's definition is used.

$$
\zeta_{\mathrm{R}}=\frac{\Delta p_{\mathrm{c}}}{\frac{1}{2} \rho w_{1}^{2}}
$$

The following relationship between $\zeta_{\mathrm{R}}$ and $c_{\mathrm{D}, \mathrm{R}}$ can be found in [4]:

$$
c_{\mathrm{D}, \mathrm{R}}=\zeta_{\mathrm{R}} \frac{s_{\mathrm{R}}}{c_{\mathrm{R}}} \cos \alpha_{\infty}
$$

The pressure loss coefficient can be taken from a diagram [5] which describes the dependence of this coefficient (denoted by $\omega$ ) and of deviation angle on the angle of attack (denoted by $i$ ). It contains values measured using modified NACA 65A10 airfoils which are also used in the UL-39 propulsion unit fan.

The angle of attack results from the CFD calculation made in [2]. Therefore, $\alpha_{\infty}=1.1^{\circ}$ (see figure 4). From the diagram in figure 9 , the value of $\zeta_{\mathrm{R}}=0.03$ can be read.

The pitch-to-chord ratios $s_{\mathrm{R}} / c_{\mathrm{R}}$ of the UL-39 fan rotor are different for each radius and can be found in [6]. For example, $s_{\mathrm{R}} / c_{\mathrm{R}}=0,704$ at the hub. The rotor blade drag coefficient is then:

$c_{\mathrm{D}, \mathrm{R}}=\zeta_{\mathrm{R}} \frac{s_{\mathrm{R}}}{c_{\mathrm{R}}} \cos \alpha_{\infty}=0.03 \times 0.704 \times \cos 1.1^{\circ}=0.0211$

This calculation is to be repeated in the other sections of the rotor vane. The results of this calculation are 
summarized in table 1 . Since the angle of attack is nearly constant along the rotor blades, the pressure loss coefficient is considered to be constant as well.

Table 1. Rotor blade drag coefficients in eight circumferential sections of the rotor vane.

\begin{tabular}{|r|r|r|r|}
\hline Section No. & $r(\mathrm{~mm})$ & $s / c$ & \multicolumn{1}{l|}{$c_{\mathrm{D}, \mathrm{R}}$} \\
\hline 1 & 126 & 0.704 & 0,021 \\
\hline 2 & 148 & 0.897 & 0,027 \\
\hline 3 & 170 & 0.975 & 0,029 \\
\hline 4 & 192 & 1.324 & 0,040 \\
\hline 5 & 214 & 1.549 & 0,046 \\
\hline 6 & 236 & 1.775 & 0,053 \\
\hline 7 & 258 & 1.999 & 0,060 \\
\hline 8 & 280 & 2.216 & 0,066 \\
\hline
\end{tabular}

Therefore, the ratio of the backflow velocity to the mean undisturbed flow velocity will be a function of two variables:

$$
\frac{v_{0}}{v_{\infty}}(r, x)=\frac{1.6 \sqrt{c_{\mathrm{D}, \mathrm{R}}(r)}}{\sqrt{\frac{x}{c_{\mathrm{R}}(r)}+0.025}}
$$

This function is presented as a diagram in figure 8 . It is clear that the difference between the velocity ratios along the blades is not significant. The curve describing this dependence is very steep for the first $50 \mathrm{~mm}$ and, conversely, very flat further downstream.
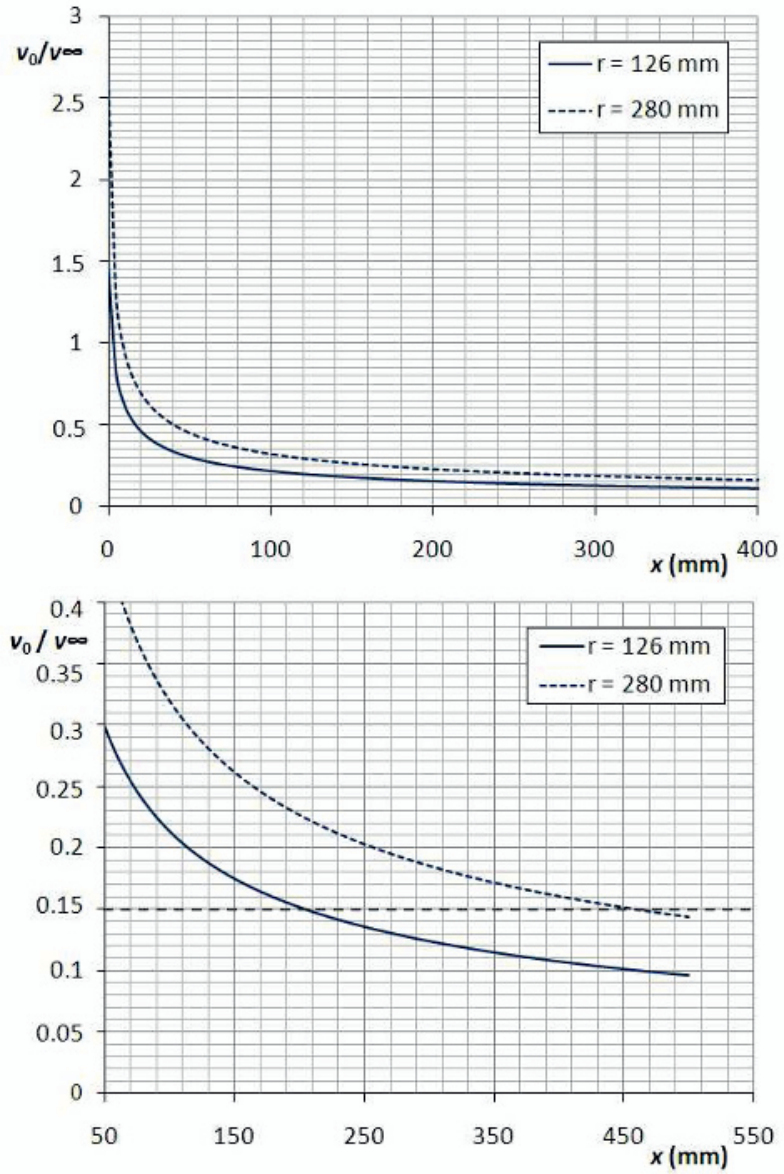

Figure 8. Wake velocity defect as a function of distance.
At the outer radius of the rotor, where the backflow velocity is the highest, a value of $v_{0} / v_{\infty}=0.2$ is achieved in a distance of $260 \mathrm{~mm}$. A value of $v_{0} / v_{\infty}=0.15$ and 0.10 corresponds to $\mathrm{x}=460$ and $1035 \mathrm{~mm}$, respectively. In longer distances behind the rotor, the calculation is clearly not valid anymore since the shape and area of the duct are different.

This means that if the measuring tubes are to be placed in a distance between 350 and $410 \mathrm{~mm}$, it is necessary to count on a backflow velocity of $v_{0}=(0.16 \div 0.17) v_{\infty}$ (at the outer diameter), not taking into account the widening of the wake.

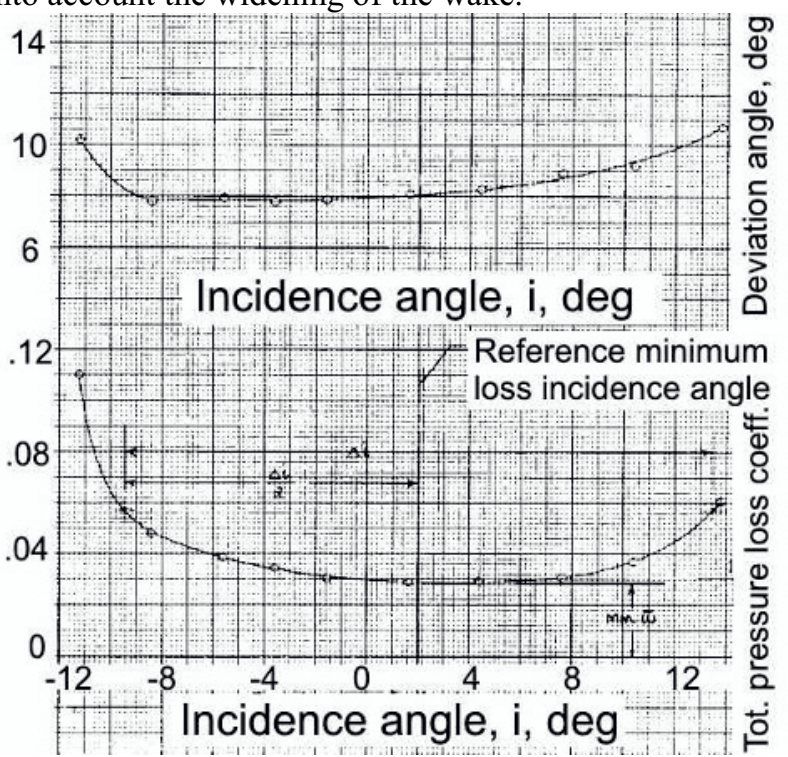

Figure 9. Deviation angles and total pressure loss coefficients of a NACA 65A10 airfoil. [5]

However, from the fundamentals of aerodynamics, it is known that the wake behind airfoils becomes wider when passing downstream (as sketched in figure 7). So now we need to focus our attention on the width of the wake.

Theoretically, an even velocity distribution would be achieved in a distance in which the width of the wake (denoted by $\delta$ ) equals one half of the vane blade pitch. For roughly estimating the coordinate of this place, we will used relationships described in [7].

The equations found in [7] describe the wake width as a function of the longitudinal coordinate and rotor blade drag coefficient:

$$
\frac{\delta}{s}=f\left(\frac{x}{c}, c_{\mathrm{D}, \mathrm{R}}\right) \text { and } \frac{\delta}{c}=f\left(\frac{x}{c}, c_{\mathrm{D}, \mathrm{R}}\right)
$$

According to [7], these relationships can be used for compressor blade vanes in a wide range of pitch-to-chord ratios (or solidities).

For high-solidity vanes with a value of $s / c \leq 1$ it is recommended to normalize the width of the wake with the blade pitch. The following equation is used:

$$
\frac{\delta}{s}=\frac{0.31875 \frac{x}{c} \sqrt[8]{c_{\mathrm{D}, \mathrm{R}}}+0.048}{0.268125 \frac{x}{c} \sqrt[8]{c_{\mathrm{D}, \mathrm{R}}}+1}
$$


For low-solidity vanes $(s / c>1)$, on the other hand, the width of the wake is normalized with the blade chord. Therefore:

$$
\frac{\delta}{c}=\frac{0.2375 \frac{x}{c} \sqrt[8]{c_{\mathrm{D}, \mathrm{R}}}+0.034125}{0.357 \frac{x}{c} \sqrt[8]{c_{\mathrm{D}, \mathrm{R}}}+1}
$$

Since the rotor blades of the UL-39 fan are relatively long and their chord is not constant over their length, both these relationships will be used at different radii. As can be seen from table 1, in sections 1 to 3 Eq. (7) will be used while in sections 4 to $8 \mathrm{Eq}$. (8) is valid.

The results of these equations, expressed by $\delta / s$, are presented in figure 10. It can be observed that, according to these calculations, the even velocity distribution $(\delta / s=$ 1 ) is theoretically achieved in a distance of $x=210 \mathrm{~mm}$.

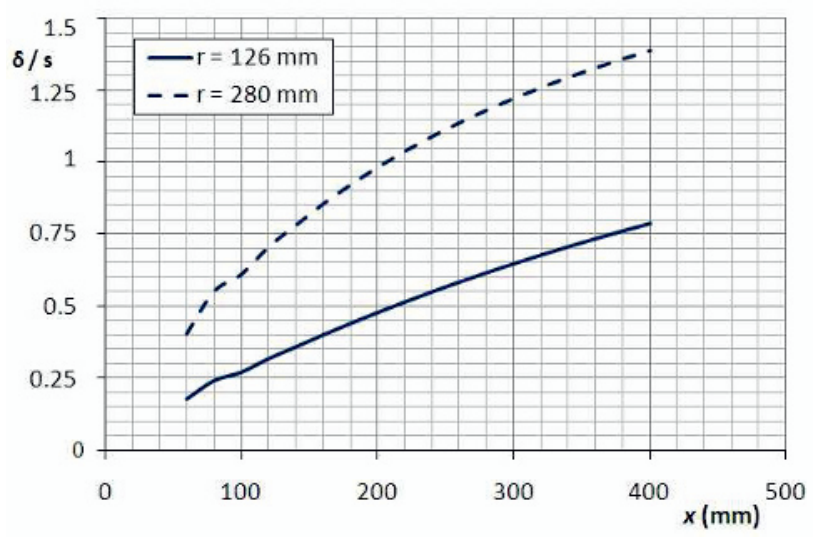

Figure 10. Wake thickness as a function of distance.

This leads to a conclusion that the velocity distribution in distances between 350 and $410 \mathrm{~mm}$ downstream of the rotor should not be extensively affected.

Placing the sensing tubes in these distances is therefore possible. The real distance will be determined during their assembly.

\subsection{Distribution of the sensing tubes in the channels}

Now that the possible distance of the sensing tubes downstream of the fan is known, the distribution of measuring points in the sections of the inlet and outlet channel should be determined

Since, apart from total pressure, we also intend to measure static pressure downstream of the fan, it is necessary to bear in mind the fact that a circumferential velocity component will always be present in the flow field downstream of the fan (except for, theoretically, the design point).

This means that a swirling motion of the air will take place inside the channel and that the static pressure distribution over the respective channel section will be uneven. Around the axis, the static pressure will be lower than near the channel walls. It is therefore not possible to measure its value using bores in the channel walls. The static pressure sensors should be placed directly in the sensing tubes.
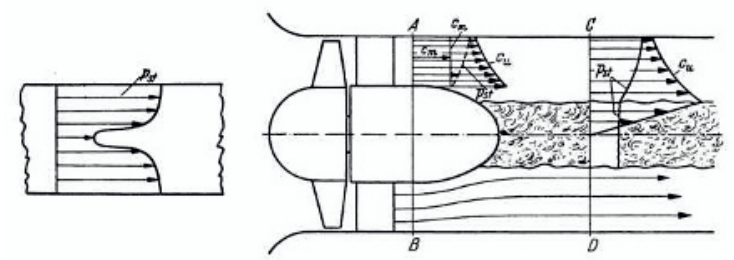

Figure 11. A scheme of vortex generation behind a fan [8]

For measuring the total and static pressure inside the outlet channel, three radial lines should be used and the mean value in each circumferential section will then be computed (at least two radial lines should be used according to [8]).

In places where the sensing tubes will enter the channel, it is necessary to strengthen the composite channel walls with inserts.

In the inlet channel, a few ribs equipped with total pressure sensing bores will be placed (in the left part of figure 13, these places are marked by yellow lines). The connecting tubes will go through the inside of the channel leading edge, where enough space is available for their placement. The resulting "measuring inlets" will be available for quickly putting on during measurement in a wind tunnel or in the laboratory. Another advantage of this arrangement is that no traversing is needed which would require a traversing mechanism to be designed while also extensively consuming time and fuel.

There are also two minor disadvantages - a slight blockage of the inlet section and the influence on the flow field around it. For similar reasons, ladder probes will be used downstream of the fan.

\section{The instrumentation}

\subsection{Instrumentation for measuring the velocity distribution}

In this experiment, measuring the flow field pulsations caused by turbulence is not required. Its goal is just the opposite - the mean values of total and static pressure and velocity need to be measured. Therefore, using anemometric probes is not necessary. Conventional Pitot and Prandtl tubes will be used instead. For determining the direction of the velocity vectors downstream of the fan, multi-hole probes will be used.

\subsection{Instrumentation for controlling the flow rate}

The air flow rate will be controlled by a suitable throttling device. According to the arrangement of the whole propulsion unit, this device should be placed in its aft part (inside the outlet nozzle or in a chamber downstream of it).

A throttling valve is one of the devices that may be used for controlling the flow rate. Conventional valves used in air conditioning fans are not designed for the range of velocities encountered in the UL-39 propulsion unit (a mass flow rate of up to $20 \mathrm{~kg} / \mathrm{s}$ ). Throttling valves 
for heating systems or industrial compressors could be used but they can be rather expensive.

Another major disadvantage of using throttling valves is their considerable influence on the flow field to a long distance upstream of the valve. This leads to a decrease of the measurement accuracy as the measuring conditions start to vary with the real case.

Using a variable-geometry outlet nozzle is also an option. The laboratory if the Institute of Aerospace Engineering is equipped with converging nozzles of various exit diameters. However, they are unable to cover the whole range of flow rates and unavailable in a sufficient quantity to ensure a satisfying stepwise flow rate control.

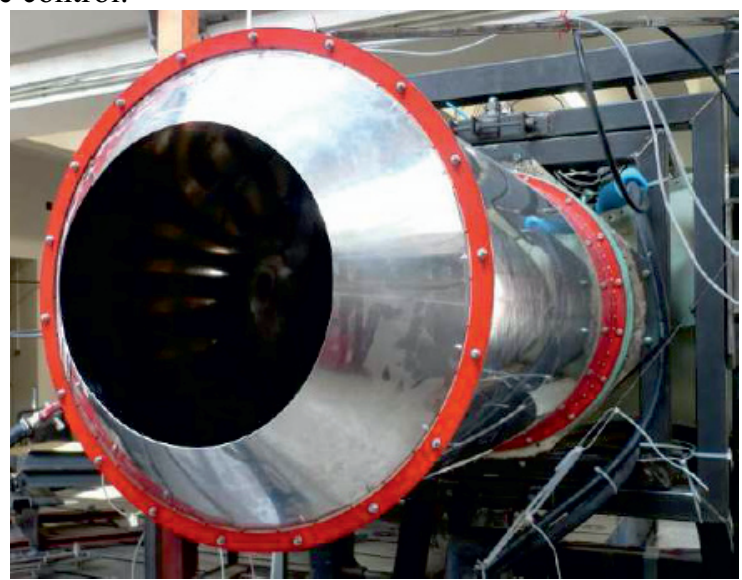

Figure 12. One of the exit nozzles used by the Department of Aerospace Engineering [9]

Seemingly, the most suitable controlling element for this application will be a strainer with a variable density which means that several strainers will be used placed behind each other. The control will also be stepwise in this case but with a sufficient range and quantity of steps for measuring the whole extent of the fan characteristic curve.

The measurement of the UL-39 fan characteristic curve is highly specific because the fan together with its inlet and outlet channel forms an integrated system.
If the fan was separated from the influences of its channels, its operational behaviour would be completely different.

When air conditioning fans are measured, special elements are placed inside the piping to make the velocity distribution more even and thus help the fan to operate independently from the piping. Taking these measures in the case of the UL-39 fan would cause deviations from the real operating conditions.

\section{The measurement procedure}

\subsection{Visualising the flow in the inlet channel}

The first step of the experiment will be flow visualisation in the measuring section of the inlet channel. The flow will be visualised using smoke or cotton. One of its goals is checking whether the flow field is qualitatively the same in both branches of the inlet channel. Furthermore, the presence of transversal velocity components or vortices can be detected.

Since the measuring stand is made if composites and is not equipped with windows, visualising the flow in other sections is not possible.

\subsection{Determining the velocity directions downstream of the fan}

For determining the directions of the absolute velocity vectors downstream of the fan rotor, cylindrical of multihole probes will be used.

Measuring the velocity directions is important for two reasons. First, the angle of the Prandtl tubes downstream of the fan will be determined, and second, the knowledge of the circumferential velocity components at various offdesign conditions can be gained.
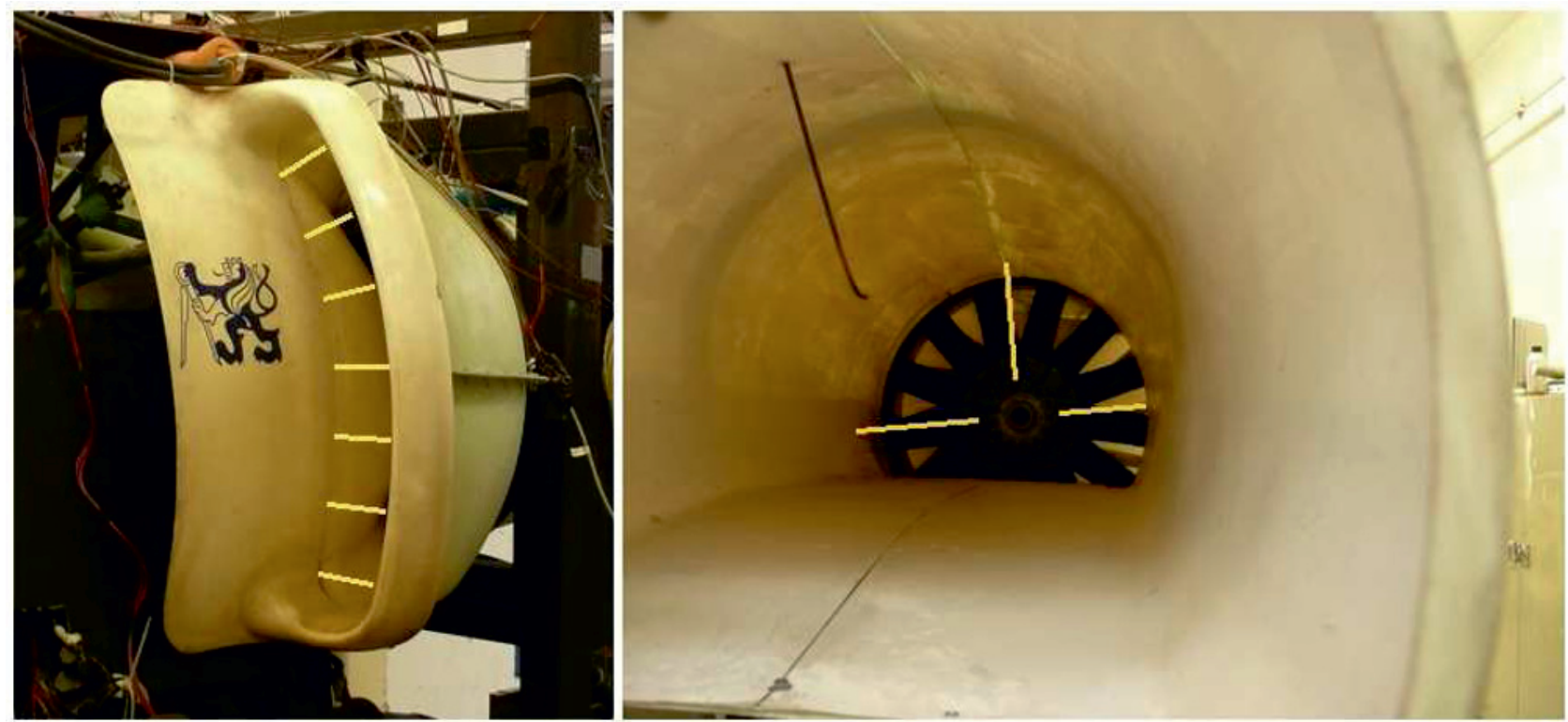

Figure 13. Position of probes in the two measuring planes. 


\subsection{Measuring the velocity distribution}

The velocity idstribution will be measured dowstream of the fan. The Prandtl tubes should be directed against the flow. The tubes will be distributed over the section of the piping using the equal area rule.

The velocity will not be measured near the axis since an extreme value would be captured there.

The radii for placing the Prandtl probes can be computed using the following equation:

$$
r_{i}=R \sqrt{\frac{i-\frac{1}{2}}{n}}=R \sqrt{\frac{2 i-1}{2 n}}
$$

At each radius, a velocity value will be measured which will be considered mean velocity in its annulus. The mean value over the whole section which determines the volumetric flow rate will then be computed using graphical or numerical integration (see [8] or [10] for details). The flow rate is computed using the following equation:

$$
\dot{V}=\iint_{S} w \mathrm{~d} S=\bar{w} S
$$

According to the calculations made in [6], the axial velocity component inside the fan should be $c_{\mathrm{a}}=90 \mathrm{~m} / \mathrm{s}$. A Mach number of 0,264 corresponds to this velocity considering the conditions in a height of $h=0 \mathrm{~m}$ (ISA), similar to these expected in the laboratory during the experiment. Therefore, the flow in the absolute coordinate system is assumed to be incompressible. The mass flow rate is then computed using this simple equation:

$$
\dot{m}=\rho_{\infty} \iint_{S} w \mathrm{~d} S=\rho_{\infty} \bar{w} S
$$

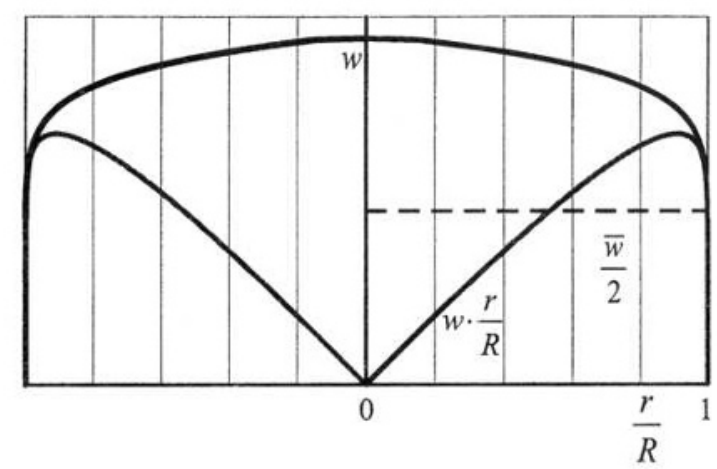

Figure 14. Velocity profile graphical integration [10].

The mean values of total pressure behind the fan will be determined by averaging the measured values in each measuring plane. From these values, the total pressure ratio $\pi_{\mathrm{V}}$ of the fan can be computed and then plotted in the characteristic curve.

\subsection{Conditions at the design point}

The measurement described above will, first of all, be carried out at the design conditions of the fan (according to [6]). It means using an unthrottled exit nozzle with an exit diameter of $450 \mathrm{~mm}$ and reducing the ambient conditions during measurement to the conditions corresponding to $h=0 \mathrm{~m}$ (ISA).

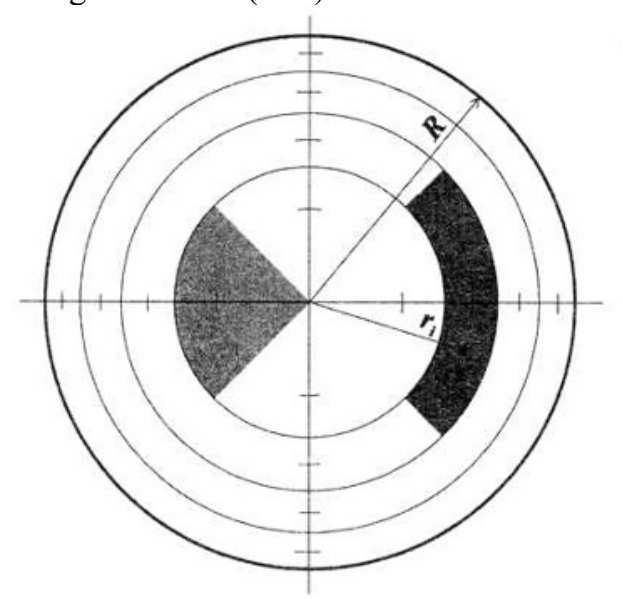

Figure 15. Division of the outlet channel cross-section using the equal area rule. [10]

\subsection{Plotting the characteristic curve}

Afterwards, the whole characteristic curve of the fan will be measured. Each curve, corresponding to a respective shaft speed, can be plotted according to the known values of pressure ratio and mass flow
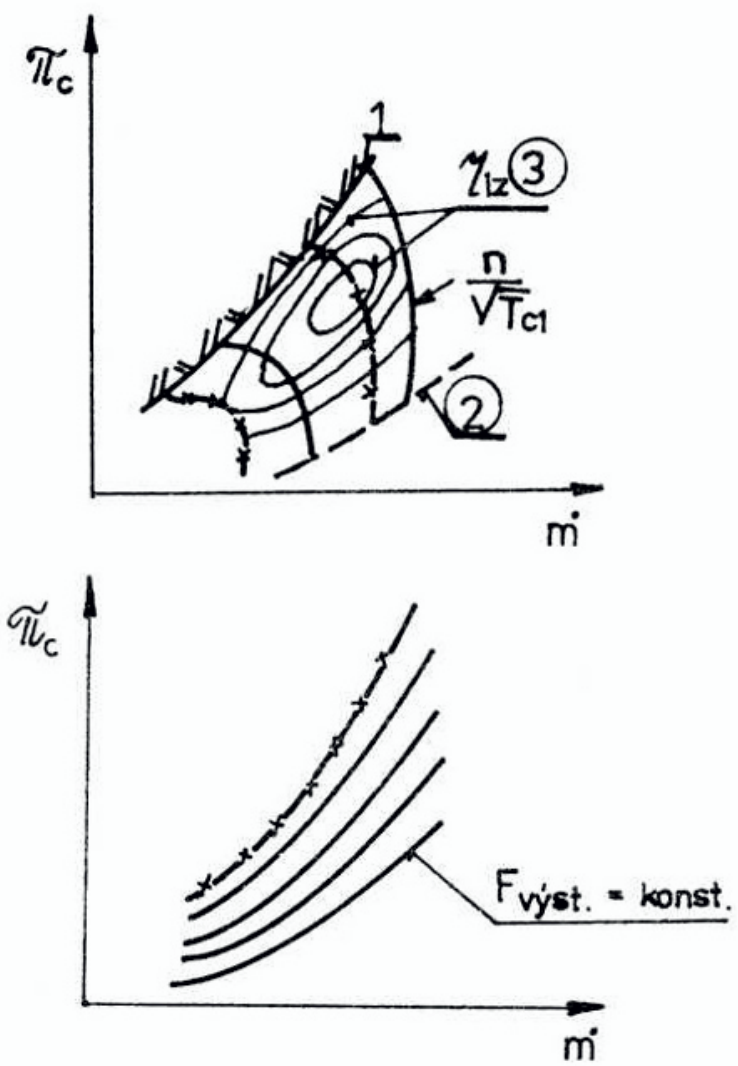

Figure 16. The fan characteristic curve (above) and the alternative means of measuring it (below) [11]

When measuring each of these curves, the flow rate is controlled by a throttling device while the shaft speed is kept constant. This leads to a change of the fan total pressure ratio. Each curve should be constructed using at least about ten points (ten settings of the throttling 
element). This technique, although often used in practice, is not suitable for the UL-39 fan propulsion unit.

Considering the difficulty of keeping the combustion engine speed constant as well as the necessity of switching the strainers several times at each speed, the measurement will be carried out using an alternative technique, described in [11].

A set of curves in the pressure ratio-flow rate coordinates will be measured, each of them corresponding to a constant nozzle exit area (a constant throttling device setting, see the bottom part of figure 16).

The curves corresponding to the respective shaft speeds may then be constructed by connecting the appropriate sets of points in these coordinates. Slight deviations of the shaft speed, which may occur during the experiment, may be corrected using equations presented in [11].

This way, for each throttling element setting, the fan will be accelerated from the lowest speed to the highest. This makes the measurement more practical and faster while not negatively affecting its accuracy.

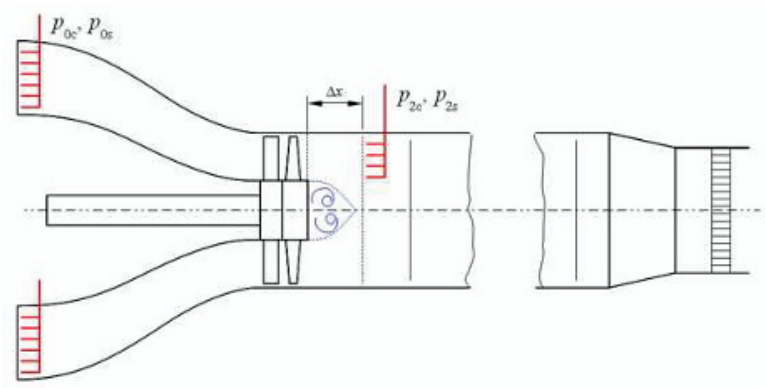

Figure 17. A scheme of the future stand.

The characteristic curve can then be reduced to the standard conditions (see [11]) to make it comparable with future measurements or other types of axial turbomachines.

\subsection{Evaluation and further steps}

The characteristic curve of the fan, as described above, is an important indicative factor of its operational behaviour. The operating point should lie in a sufficient distance from the surge limit and in the area of the greatest fan efficiency. The efficiency at various points can be determined by using total temperature sensing devices together with pressure sensors.

Another important result of the experiment will be the knowledge of the velocity distribution in the inlet channel and downstream of the fan. So far, only CFD calculations were used to determine the velocities in these areas. The experiment should help to validate the calculations made.

Last but not least, the values of the pressure ratio and flow rate in the design point will be checked. Furthermore, the velocity direction should be measured in this point and any deviation from the axial direction determined. These calculations should validate the onedimensional design calculations of the present fan.

\section{Conclusions}

In this paper, the redesign of a measuring stand for a ducted fan aircraft propulsion unit was described, together with the procedures of future measurements.

The results of the experiments will be used during the development of a new fan for this propulsion unit which should produce less noise or increase the cruise speed of the aircraft.

Since any measurements of the fan characteristic curve or the design point conditions have not yet been made, the experiment will also be used for validating the design calculations of the present fan and the location of the design point on the characteristic curve.

\section{References}

1. J. H. Dittmar. Methods for Reducing Blade Passing Frequency Noise Generated by Rotor-wake-Stator Interaction. Technical Memorandum. (Washington: NASA, 1972). Report No. NASA TM-X 2669.

2. E. Ritschl. Analýza tvaru vstupnich ploch sacího kanálu dmychadla. Doctroal Thesis. (CTU in Prague, Faculty of Mech. Eng., 2009)

3. Z. Ilich. Rekonstrukce výstupního kanálu ventilátorového pohonu malého sportovního letounu. Master's thesis. (CTU in Prague, Faculty of Mech. Eng., 2012)

4. I. R. Schwartz, H. T. Nagamatsu, W. C. Strahle. Aeroacoustics: Fan Noise and Control; Duct Acoustics; Rotor Noise. Technical Papers from AIAA 2nd Aero-Acoustics Conference. (New York: AIAA, Cambridge: MIT Press, 1976) ISBN 0-915928-09-4

5. S. Lieblein. Incidence and Deviation Angle Correlations for Compressor Cascades. (Cleveland: NASA, 1959)

6. R. Poul. Termodynamický a aerodynamický návrh axiálního ventilátoru $v$ uspořádání rotor-stator $a$ predstator-rotor. Research report. (CTU in Prague, Faculty of Mech. Eng., 2009)

7. R. K. Majjigi, P. R. Gliebe.. Development of a Rotor Wake/Vortex Model. Volume I - Final Technical Report. Final Contractor Report. (Washington: NASA, 1984) Report No. NASA CR 174849

8. B. Eck. Ventilatoren. 6. Aufl. (Berlin, Heidelberg, New York: Springer, 2003) ISBN 3-540-44058-5

9. M. Helmich. Tests of the Propulsion Unit of an Unconventional Ultralight Aircraft. In: Studentská tvưrči činnost. Sborník 2013. (Prague: CTU in Prague, 2013) ISBN 978-80-01-05232-7

10. T. Matuška. Experimentální metody $v$ technice prostředi. 1st Ed. (Prague: CTU in Prague, 2005) ISBN 80-01-03291-4

11. P. Šoch, J. Vrátný, J. Mařík. Mechanika tekutin experimentálni metody. 1st Ed. (Prague: CTU in Prague, 1989) 